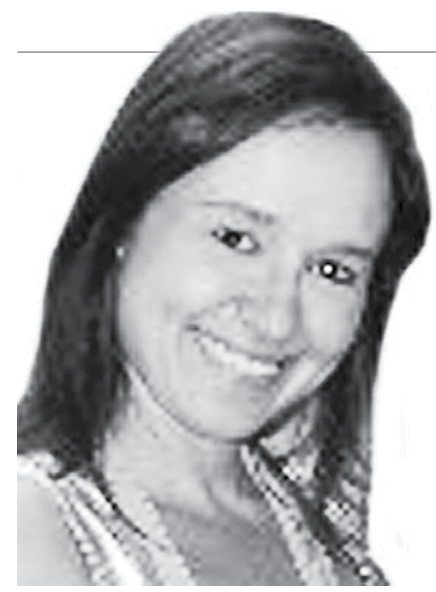

\title{
$O$ impacto dos jogos eletrônicos na propensão da geração $Y$ à cooperação ou competição no ambiente corporativo
}

\author{
The impact of electronic games on the propensity of millennials \\ cooperation or competition in the corporate environment
}

\section{El impacto de los juegos electrónicos en la propensión de la generación del milenio cooperación o la competencia en el entorno corporativo}

O objetivo deste estudo foi analisar, à luz da teoria da interdependência social de Deustch (1973), o impacto dos jogos eletrônicos na propensão da geração Y à cooperação ou competição no ambiente organizacional. A teoria diz que a interdependência entre indivíduos pode ser positiva (cooperação) ou negativa (competição). A discussão teórica parte de uma explanação sobre as diferentes gerações que interagem em um mesmo contexto organizacional. A amostra de 901 respondentes foi composta por alunos de pós-graduação de uma Instituição de Educação Superior (IES) particular, membros de uma rede social, leitores de um blog de economia, funcionários do SEBRAE/ES e contatos pessoais da autora. Utilizou-se também o método snowball na coleta dos dados. O banco de dados inicial contou com 33 variáveis expressas com base na escala de diferencial semântico com classificação de sete pontos, e o questionário esteve hospedado na plataforma SurveyMonkey. Utilizou-se o modelo Log-Linear por ser o mais adequado para análise dos dados qualitativos. Por fim, os resultados sugerem que os jogos eletrônicos influenciam jogadores da geração Y da amostra a maior propensão a cooperar, levantando a possibilidade de se confirmar que há predisposição maior para cooperar do que para competir.
The aim of this study was to analyze, according to the social interdependence theory of Deustch (1949), the electronic games impacts in generation $Y$ cooperation or competition attitudes in organizational environment. This theory relates to relational concepts, discussing the interdependence between people may be positive (cooperation) or negative (competition). The theoretical discussion starts in a short explanation about the different generations that interact in an equal organizational environment, discussing the generational profiles, as well the generation Y peculiarities. Then, the social interdependence theory was discussed as a way of conceptualize cooperative and competitive behaves. The survey was conducted from a sample of 901 respondents, consisting of students graduate from a particular Higher Education Institution (HEI), members of a social network, a blog reader of economy, officials SEBRAE / ES and personal contacts of the author. The snowball method was also used in data collection. The initial database included 33 variables expressed based on the semantic differential scale with seven points classification, whose ends are associated with bipolar labels that have semantic meaning. The questionnaire was scanned by SurveyMonkey platform and available at URL itself to allow remote access units research, besides the rapid tabulation of results and analysis. The Log Linear model was chosen to be the most suitable for qualitative analysis of categorical data. Finally, the results suggest that electronic games influence generation $Y$ players to the greater propensity to cooperate, raising the possibility of confirming that there is greater susceptibility to cooperate than to compete.
El objetivo de este estudio fue analizar, De acuerdo con la teoría de la interdependencia social del Deustch (1949), los impactos de juegos electrónicos en la generación Y Cooperación o actitudes de competencia en el entorno de la organización. Esta teoría relaciona con conceptos relacionales, discutiendo la interdependencia entre las personas puede ser positivo (Cooperación) o negativo (competencia). La discusión teórica se inicia en la breve explicación sobre los diferentes generaciones Que interactúan en un ambiente organizacional igual, discutiendo los perfiles generacionales, así como las peculiaridades de la Generación Y. Entonces, la teoría de la interdependencia social se discutía la forma de conceptualizar de comporta cooperativos y competitivos. La encuesta se realizó a partir de una muestra de 901 encuestados, que consta de postgrado a estudiantes de una institución privada de educación superior (IES), los miembros de una red social, el lector del blog de economía, officals de SEBRAE / ES y los contactos personales del autor. El método de bola de nieve se utilizó también en la recopilación de datos. La base de datos inicial incluyó 33 variables expresso basada en la escala de diferencial semántico con la clasificación de siete puntos, cuyos extremos están asociados con etiquetas bipolares Que tienen significado semántico. El cuestionario fue analizado por la plataforma de SurveyMonkey y disponible en URL en si para permitir la investigación unidades de acceso remoto, sucia la rápida tabulación de los resultados y el análisis. El modelo de registro lineal fue elegido para ser el más adecuado para el análisis cualitativo de los datos categóricos. Por último, los resultados sugieren Que los juegos electrónicos influyen en los jugadores de la Generación Y a la mayor propensión a cooperar, aumentando la posibilidad de confirmar Que hay una mayor susceptibilidad a cooperar que competir. 
Palavras-chave: Geração Y, Cooperação, Competição, Jogos eletrônicos.

\section{Autores: \\ Luciana Genelhu Zonta}

Mestre em Administração pela FUCAPE Business School (2012), Especialista pela PUC-SP em Economia e Gestão das Relações de Trabalho (2004), Graduada em Administração de Empresas pela Universidade Federal do Espírito Santo (2002). Atualmente é docente e Coordenadora do MBA em Gestão Estratégica de Pessoas da Faculdade Estácio de Vitória/ES.

Email:Igzonta@hotmail.com

\section{Introdução}

O mercado de trabalho aponta que, pela primeira vez na história, as organizações acolhem profissionais, cujas idades cobrem uma diferença de mais de 40 anos (LOMBARDIA; STEIN; PIN, 2008), fazendo interagir, dessa forma, em um mesmo contexto organizacional até quatro gerações distintas, ou seja, tradicionais (ou veteranos), baby boomers, geração X e geração Y ou trabalhadores do milênio (SMOLA; SUTTON, 2002; LANCASTER; STILLMAN, 2005).

De acordo com Balassiano (2009), a cada 20 anos, aproximadamente, uma nova geração surge, e os efeitos das transições entre elas são verificados de quinze a vinte anos depois. Transformações sociais e econômicas, aliadas a vários outros fatores, tais como o conjunto de vivências comuns e a aproximação das idades impactam na história de uma geração (LOMBARDIA; STEIN; PIN, 2008), sendo que suas características influenciam o modo de ser e de viver das pessoas nas sociedades (VASCONCELOS et al., 2009).

Assim, a gestão das diferenças entre gerações é preponderante, não por razões humanistas, mas por ser um imperativo dos negócios (LOMBARDIA; STEIN; PIN, 2008). Dencker; Joshi; Martocchio (2007) e Kupperschmidt (2000) explanam a respeito de sistemas sociais que não levam em conta dinâmicas sociais pertinentes à idade que podem desencadear ou sustentar conflito de gerações, insatisfação e diminuição na produtividade no ambiente de trabalho. Autores como Beck e Wade (2004) pontuam que a aceleração das inovações tecnológicas a partir da década de 90 propiciou um maior contato da geração Y com os jogos eletrônicos, incutindo a esses sujeitos uma cultura diferente no que diz respeito à força de trabalho, centrada na liberdade de tomar decisões, nas oportunidades de aprendizagem e desenvolvimento, na comunicação aberta e no respeito pelo seu estilo de vida (LOMBARDIA; STEIN; PIN, 2008).

De acordo com DeFalco (2007), em busca da convergência entre a tecnologia e a criatividade, os games servem hoje para educação, treinamento de profissionais das mais diversas áreas, e são, hoje, meios interativos com os quais o usuário constrói hipóteses, resolve problemas, desenvolve estratégias, aprende regras e simula o real. "O hábito de jogar traz no seu bojo uma série de particularidades que podem contribuir na formação de potenciais diferenciais entre as gerações que se encontram no mercado de trabalho contemporâneo" (BALASSIANO, 2009, p. 5).

Nesse contexto, Deutsch (1973) ressalta que a interdependência entre os integrantes de um grupo pode ser competitiva ou cooperativa. Ele ainda define a cooperação como o contexto interativo em que as ações de um participante favorecem o alcance do objetivo de ambos. No âmbito oposto, na competição, o atingimento do objetivo de um membro impede os outros de atingirem os seus.

$\mathrm{Na}$ literatura tem sido comum o desenvolvimento de pesquisas relacionadas ao modo como as gerações se relacionam no ambiente organizacional, mais especificamente às reações e respostas da geração $\mathrm{Y}$, sendo foco de autores como Yee (2006) e Siitonen (2003) que estudaram o comportamento desses jovens, Rugimbana (2007) com investigações sobre suas especificidades culturais e Dencker; Joshi; Martocchio (2007) que mostraram como as normas relacionadas à idade são institucionalizadas nas organizações.

Apesar de estudos já terem sido realizados com a geração Y, não foram encontradas na literatura nacional pesquisas envolvendo o impacto dos jogos eletrônicos na propensão da geração $\mathrm{Y}$ à competição ou à cooperação no ambiente corporativo, apenas na literatura internacional. E o presente estudo contribui na revisão de práticas de gestores, sugerindo a inserção de estratégias na formação de equipes envolvendo a geração Y.

Dessa forma, a fim de preencher essa lacuna, o problema de pesquisa desse estudo é: Qual o impacto dos jogos eletrônicos na propensão da geração Y à cooperação ou competição no ambiente corporativo?

Tendo como objetivo geral analisar o impacto dos jogos eletrônicos na propensão da geração $\mathrm{Y}$ à cooperação ou competição no ambiente corporativo, à luz da teoria da interdependência social de Deustch (1973).

Assim, foram levantadas as seguintes hipóteses:

H1: Os jogos eletrônicos influenciam jogadores da geração $\mathrm{Y}$ a maior propensão a cooperar.

H2: Os jogos eletrônicos influenciam jogadores da geração $\mathrm{Y}$ a maior propensão a competir.

O estudo se justifica pela importância do desenvolvimento de pesquisas relacionadas ao comportamento da geração $\mathrm{Y}$ no país, colaborando com o avanço da teoria de Gestão de Pessoas, pois Gilbert (2011) ressalta que, gerentes acostumados a usar certas práticas para envolver boomers vão ter que mudar os seus caminhos e práticas, caso esperem contratar e manter o grupo mais novo fortemente empregado.

\section{Revisão de literatura}

\section{Os perfis geracionais}

Com a virada do século, o conceito de gerações recupera o seu espaço nas análises sociológicas que não indicam somente as diferenças de classe, mas ainda as desigualdades de gênero, étnico raciais, culturais e geracionais (MOTTA; WELLER, 2010). Para que seja possível entender uma geração, é necessário contextualizá-la a partir das anteriores (VASCONCELOS et al., 2009).

No mesmo contexto, para compreender como uma geração difere da outra, é preciso que se perceba como cada uma delas forma um conjunto de crenças, valores e prioridades, ou seja, paradigmas, consequências diretas da época em que cresceram e se desenvolveram (CHIUZI et al., 2011).

Diversas pesquisas (ALVES, 2004; BALASSIANO, 2009; DENCKER; JOSHI; MARTOCCHIO, 2007; FERREIRA, 2010; FEIXA; LECARDDI, 2010) abordam os comportamentos entre gerações sob diferentes aspectos e "embora as motivações variem dependendo do campo do conhecimento, os objetivos seguem a mesma direção: traçar perfil; identificar características idiossincráticas; e estabelecer paralelos entre atitudes, habilidades e comportamentos" (BALASSIANO, 2009, p. 3). 
As gerações podem ser classificadas conforme a sua faixa etária em: a) tradicionalistas ou veteranos (nascidos antes de 1947); b) baby boomers (nascidos até 1964); c) geração X (nascidos ente 1965 e 1977); e d) geração Y ou baby gamers, (nascidos a partir de 1978) (BECK; WADE, 2004; COIMBRA; SCHIKMANN, 2001; LANCASTER; STILLMAN, 2005; LOMBARDIA; STEIN; PIN, 2008; VELOSO et al., 2008).

Algumas diferenças entre as gerações, comparando e contrastando comportamentos são apresentadas no Quadro 1.

\section{Quadro 1 - Resumo sobre as diferenças entre gerações}

\begin{tabular}{|c|c|c|c|c|}
\hline Perspectiva & Tradicionais & Baby Boomers & Geração X & Geração Y \\
\hline Ética profissional & Otimista & Cética & Esperançosa \\
\hline $\begin{array}{c}\text { Postura } \\
\text { diante autoridade }\end{array}$ & Respeito & Amor/Ódio & Desinteresse & Cortesia \\
\hline Liderança por & Hierarquia & Consenso & Competência & Coletivismo \\
\hline Espírito de & Sacrifício & Automotivação & Anticompromisso & Inclusão \\
\hline
\end{tabular}

FONTE: Lombardia; Stein e Pin (2008)

McGuire et al. (2007), Crumpacker e Crumpacker (2007) e Platteau, Molenveld e Demuzere (2011) explicam que cada uma dessas gerações tem um tipo específico de perfil. Os baby boomers, por exemplo, são geralmente considerados pelo emprego de valor ao longo da vida e lealdade à empresa, enquanto a geração $\mathrm{X}$ atribui mais significado à participação, desenvolvimento, estima, trabalho em equipe e qualidade de vida. Já a geração Y é muitas vezes caracterizada como a menos focada no desenvolvimento da carreira profissional, na autonomia de tarefas, no apoio à gestão, e ativo de aprendizagem. No entanto, sua maior vantagem é que são tecnologicamente alfabetizados e altamente educados (PLATTEAU, MOLENVELD; DEMUZERE, 2011).

Para Lombardia, Stein e Pin (2008) a geração X não vê o sucesso da mesma forma como seus pais e é mais cética, mais difícil de alcançar por meios tradicionais. A geração Y é vista como uma geração de resultados, não de processos. Para eles, o importante é saber o que está acontecendo no momento para reagir rapidamente.

Para Balassiano (2009), a tecnologia desempenhou um papel crucial na delimitação e formação das quatro gerações, sendo que diversos autores indicam diferentes impactos gerados pela tecnologia na formação das pessoas (BECK; WADE, 2004; DeMARCO et al., 2007).

\section{A geração y e suas peculiaridades}

Pela diversidade de alternativas presentes, os vídeo games possibilitaram a criação de diretrizes influenciadoras da vida cotidiana dos baby gamers (BECK, WADE, 2004; DeMARCO et al., 2007; FERREIRA, 2010; SUZUKI, 2009; YEE, 2006). E o fato da geração $Y$ ter sido a última a adentrar o mercado de trabalho, ocasiona um constante desafio para gestores atraí-la e fazer com que a mesma permaneça na empresa (VASCONCELOS et al., 2009).

Para Shaw e Fairhurst (2008), caracterizam-se como independentes, autossuficientes, honestos, empreendedores e decididos, tendo a tecnologia como aliada no processo de aprendizagem. E Oliveira (2010), por sua vez, os caracteriza como curiosos questionadores e criativos; extremamente informados; conhecedores de línguas estrangeiras, sobretudo o inglês; ávidos por novas experiências; e necessitados de reconhecimento constante.

Para Lombardia, Stein e Pin (2008), essa tribo, de natureza urbana, possui características comuns que a diferenciam de outros coletivos: a) seu nível educativo é alto; b) raça, nacionalidade e religião são secundárias, os laços profissionais ou de gostos pessoais é que contam; c) buscam carreiras brilhantes, altos salários e adoram os headhunters e as multinacionais; $\mathrm{e}$ d) a rede de amizades e conhecidos está distribuída por todo o mundo ou em região ampla.

\section{Os jogos e o comportamento humano}

Vários são os teóricos unânimes nas relações cognitivas, sociais, culturais e afetivas potencializadas pelos jogos (FREUD, 1976; HUIZINGA, 2001; PIAGET, 1975; WINICOTT, 1975). E Ramos (2008) destaca o jogo eletrônico pelo grande potencial midiático utilizado para criar possibilidades de representação de papéis e constituição de mundos virtuais nos quais comportamentos são autorizados e vivenciados pelos jogadores.

Para Balassiano (2009), algumas características dos jogos refletem as mesmas situações presentes na rotina diária de qualquer coordenador, gerente ou executivo de uma empresa: a) situações que demandam respostas rápidas dos jogadores; b) capacidade de análise dos riscos envolvidos em tais decisões; c) formas de aprendizado baseadas em tentativa-e-erro; d) circunstâncias em que muitas decisões devem ser tomadas rapidamente, exigindo total imersão em dados; e e) diferentes modos de cooperar, competir e se relacionar com outras pessoas (em ambientes físicos ou virtuais). Portanto, tais comportamentos e ideias compartilhadas dos jogadores, para Deutsch (1949), podem desencadear relações de interdependência social e, o modo como a mesma é estruturada determina a forma de interação entre os indivíduos.

\section{A teoria da interdependência social}

A teoria da interdependência social (DEUTSCH, 1949; LEWIN, 1935) diz respeito aos conceitos relacionais, abordando o que acontece entre indivíduos quando há uma meta comum entre os componentes de um grupo e quando o resultado atingido por um afeta o resultado do outro. Os grupos são "todos dinâmicos" nos quais uma mudança na condição de algum membro ou de algum subgrupo muda a condição dos outros membros ou de outros subgrupos (JOHNSON et al., 1998). Para Deutsch (1973) a interdependência pode ser positiva (cooperação) ou negativa (competição). Lewin (1935) pontua que a essência de um grupo reside na interdependência de seus membros.

Johnson et al. (1998), a partir de suas pesquisas sobre aprendizagem, com base na teoria da interdependência social, apontaram as condições em que circunstâncias cooperativas, competitivas ou individualizadas interferem na realização do estudante, o ajustamento psicológico, a autoestima e habilidades sociais. Como resultado, os autores constataram que contextos cooperativos quando comparados aos competitivos refletem em uma maior motivação para o trabalho.

Sato et al. (2011) argumentam a favor da abordagem dos aspectos que sustentam a cooperação e a competição como práticas sociais, nas suas implicações em termos psicossociais e nos sentidos a elas atribuídos em diferentes contextos de trabalho.

Deutsch (1973) categoriza duas classes de processos: processos cooperativos e processos competitivos, de forma que 
ambos são interdependentes. Tal interdependência leva a ganhos mútuos nos processos cooperativos; sendo que nos competitivos para que uma das partes ganhe a outra sofrerá prejuízos.

No mesmo contexto, o autor classifica os processos a partir de seus efeitos: a) substitutividade - em processos cooperativos, seria supérfluo que uma das partes realizasse determinada atividade que a outra realiza. Por outro lado, em processos competitivos, ambas as partes devem ter interesse em realizar a mesma atividade; b) desenvolvimento de uma postura negativa (competição) ou positiva (cooperação) em relação à outra parte; e c) a capacidade de uma parte se deixar ser influenciada pela outra (no caso dos processos competitivos, essa capacidade é muito menor).

Vários autores discutiram a cooperação e a competição como positivas ou negativas (BENDASSOLLI, 2001; DEUTSCH, 1973; SATO et al., 2011) sendo que, nos mercados contemporâneos, sinais competitivos podem ser considerados elementos positivos quando o ambiente demandar este tipo específico de comportamento para o sucesso de um empreendimento (ROBBINS, 2011).

De acordo com Brotto (1999) cooperação e competição são processos distintos, porém, não muito distantes. As fronteiras entre eles são tênues, permitindo certo intercâmbio de características, de maneira que se pode encontrar, em algumas ocasiões, uma competição-cooperativa e em outras, uma cooperação-competitiva, conforme se observa no quadro 2 .

\section{Quadro 2 - Situação cooperativa e situação competitiva}

\begin{tabular}{|c|c|}
\hline Situação cooperativa & Situação competitiva \\
\hline $\begin{array}{l}\text { Percebem que o atingimento de seus } \\
\text { objetivos é, em parte, consequência da } \\
\text { ação dos outros membros. }\end{array}$ & $\begin{array}{l}\text { Percebem que o atingimento de seus } \\
\text { objetivos é incompatível com a obtenção } \\
\text { dos objetivos dos demais. }\end{array}$ \\
\hline $\begin{array}{l}\text { São mais sensiveis às solicitações dos } \\
\text { outros. }\end{array}$ & $\begin{array}{l}\text { São menos sensíveis às solicitações dos } \\
\text { outros. }\end{array}$ \\
\hline Ajudam-se mutuamente com frequência. & $\begin{array}{l}\text { Ajudam-se mutuamente com menor } \\
\text { frequência. }\end{array}$ \\
\hline $\begin{array}{l}\text { Há maior homogeneidade na quantidade } \\
\text { de contribuições e participações. }\end{array}$ & $\begin{array}{l}\text { Há menor homogeneidade na quantidade } \\
\text { de contribuições e participações. }\end{array}$ \\
\hline $\begin{array}{l}\text { A produtividade em termos qualitativos } \\
\text { é maior. }\end{array}$ & $\begin{array}{l}\text { A produtividade em termos qualitativos } \\
\text { é menor. }\end{array}$ \\
\hline A especialização de atividades é maior. & A especialização de atividades é menor. \\
\hline
\end{tabular}

FONTE: Brotto (1999)

Para Deutsch (1973), poucas são as situações na vida real que se caracterizam por serem puramente cooperativas ou puramente competitivas.

\section{Atitudes cooperativas e competitivas}

\section{Cooperativas}

Nora e Arnoldi (2004) ressaltam a relevância da cooperação quando pontuam a possibilidade da criação da linguagem entre os seres humanos, "necessárias à evolução e construção de um mundo em comum" (NORA; ARNOLDI, 2004, p.4).

A teoria da interdependência social entende a cooperação como resultante da interdependência positiva entre os alvos dos indivíduos (JOHNSON et al., 1998). Piaget (1994, p. 25) considera a cooperação como o "fazer nascer a consciência de normas ideais, dominando todas as regras". Deutsch (1973 apud RODRIGUES, 1986) aponta que membros de grupos cooperativos terão mais facilidade que membros de grupos competitivos em valorizar as ações dos companheiros conducentes aos objetivos destes, e a opor-se e reagirem negativamente a ações capazes de dificultar ou impedir a obtenção de tais objetivos.

\subsubsection{Competitivas}

Vários autores discutiram a cooperação e a competição como positivas ou negativas (BENDASSOLLI, 2001; DEUTSCH, 1973; SATO et al., 2011) sendo que, nos mercados contemporâneos, sinais competitivos podem ser considerados elementos positivos quando o ambiente demandar esse tipo específico de comportamento para o sucesso de um empreendimento (ROBBINS, 2011).

Balassiano (2009, p. 3) diz que "as barreiras impostas pelo status quo levam geralmente às reações de quem entra no cenário. A necessidade de se firmar surge como resposta à tentativa de dominação". Desse modo, o autor destaca que administrar esses conflitos impacta de forma direta no atingimento de objetivos tanto familiares quanto organizacionais.

Para Deutsch (1973), tais conflitos nem sempre levam a resultados ruins, além de ainda poderem desempenhar funções ou positivas ou negativas. Apontam-se como positivas quando permitem a prevenção à estagnação de uma relação, dá estímulo a novos interesses e à curiosidade, bem como explora a capacidade de cada indivíduo (DEUTSCH, 1973).

\section{Metodologia}

\subsection{Processo de coleta de dados}

\subsubsection{Concepção do instrumento de coleta}

Tomando por base o referencial teórico do estudo, elaborou-se uma primeira versão do questionário composto por 33 questões. Aplicou-se um pré-teste junto aos alunos (10) e professores (3) a fim de se obter uma análise crítica sobre a coerência das questões, objetividade e clareza das perguntas elaboradas, dado o conhecimento teórico destas pessoas.

Como os resultados apontaram para a falta de "validade de face" (DeVELLIS, 2003) todas as opções de respostas do instrumento foram reformuladas a partir de sugestões do grupo e revisão teórica baseada nos mesmos autores. Assim, considerando a fase piloto da pesquisa foram reformuladas afirmações (closed-ended questions) que permitissem mensurar a presença ou intensidade de comportamentos que levassem à operacionalização dos conceitos subjacentes da dimensão.

\section{Coleta de dados}

O banco de dados inicial contou com 33 variáveis expressas com base na escala de diferencial semântico com "classificação de sete pontos cujos extremos estão associados a rótulos bipolares que apresentam significado semântico" (MALHOTRA, 2004, p. 267). O questionário foi digitalizado por meio da plataforma SurveyMonkey e disponibilizado em URL própria a fim de permitir o acesso remoto das unidades da pesquisa, além da rápida tabulação dos resultados e posterior análise.

A coleta de dados foi realizada em uma Instituição de Educação Superior particular, em uma rede social (Facebook), em um blog, bem como no SEBRAE/ES. Houve também a utilização do método snowball, ou seja, amostragem em bola de neve, sendo que, o convite para a participação na pesquisa, bem como a solicitação para que o mesmo fosse disseminado, foram enviados por email para ex-alunos e pessoas que compõem a rede de relacionamento da autora do trabalho. 
A justificativa para a escolha da amostra deve-se ao fato da facilidade de acesso aos respondentes, com o intuito de se garantir maior adesão de participações, uma vez que a mobilização na IES, unidade representativa na pesquisa, foi feita via plataforma institucional.

A partir de julho de 2012 o link do questionário foi disponibilizado na IES para acesso remoto por um período de 60 dias. Paralelamente, também foi disponibilizado nas outras unidades da pesquisa.

\section{Técnica de análise}

O estudo utiliza o modelo de Regressão Log Linear por ser o mais adequado para análise dos dados qualitativos. Para Biagioni (2010) essa variação do modelo de regressão linear clássico apresenta ao pesquisador os diferentes graus de correlação entre uma variável dependente e outras explicativas, sendo a variável dependente o local onde repousa a questão a ser explicada de acordo com o comportamento (variância) das variáveis independentes.

Como contribuição para o entendimento geral do estudo, as variáveis utilizadas nos cálculos e em suas análises serão descritas da seguinte forma: A variável explicativa "Hábito de Jogar" será representada pelas letras J (1 para jogador e 2 para não jogador), e a variável gênero será representada pela letra $\mathrm{G}$ ( 1 para feminino e 2 para masculino), sendo as variáveis respostas (dependentes) representadas pelo código VX (variável), seguidas pelo índice numérico que as representam.

Ressalta-se que os resultados apresentados são dos modelos ajustados do modelo log linear, ou seja, com a eliminação de alguns parâmetros do modelo saturado, os valores esperados são bem próximos dos valores observados. A técnica que foi utilizada para chegar a este modelo foi a Backward Elimination, ou seja, a ideia desse método de seleção por eliminação é obter o melhor subconjunto de variáveis através da sucessiva remoção das variáveis do modelo (MORAIS Jr, 2011).

É importante salientar que, as variáveis explicativas "hábito de jogar" e "gênero" são associadas, o que não será apresentado nos modelos, já que o interesse consiste nas variáveis dependentes, logo, não serão abordadas. Todos os efeitos foram avaliados sob um nível de significância de 5\%. Além disso, para que fosse possível a aplicação do modelo, optou-se por aglomerar as categorias com maiores frequências de cooperação ou competição, e as de menores frequências dos mesmos. Feito isto, o número de células com baixa frequência de respostas foi minimizado.

O Quadro 3 mostra os códigos com as variáveis que foram utilizadas na construção do modelo log-linear tabela de contingência. Com isso, foi possível traçar nos respondentes as atitudes de "cooperação" e de "competição". As respostas foram dispostas com base na escala de Likert.

\section{Quadro 3 - Relação dos códigos das variáveis dependentes utilizadas no estudo}

\begin{tabular}{|c|c|}
\hline \multicolumn{2}{|r|}{ Cooperação e Competição } \\
\hline Código & Descrição \\
\hline V1 & $\begin{array}{l}\text { "O ambiente de trabalho é formado por diversas gerações que trazem } \\
\text { consigo diferentes valores, habilidades técnicas e conhecimentos. } \\
\text { Minimizar os efeitos dessas diferenças e formar equipes harmônicas que } \\
\text { aumentam o desempenho (tanto individual quanto do grupo) tem sido um } \\
\text { dos grandes desafios enfrentados pelas organizações. Entre colaborar } \\
\text { com os colegas para todos ganharem ou não colaborar para que meu } \\
\text { trabalho se sobressaia, eu prefiro colaborar" }\end{array}$ \\
\hline
\end{tabular}

\begin{tabular}{|l|l} 
V3 & $\begin{array}{l}\text { "Na escolha de uma empresa para trabalhar, eu prefiro um ambiente } \\
\text { onde a COLABORAÇÃO para a obtenção de resultados é": Fundamental; } \\
\text { Importante; ou Irrelevante. }\end{array}$ \\
V4 & $\begin{array}{l}\text { "O mercado de trabalho pode ter ambientes que variam entre aqueles em } \\
\text { que as pessoas trabalham juntas, para que todos ganhem méritos iguais, } \\
\text { ou aqueles onde as pessoas preferem trabalhar individualmente, para } \\
\text { ganharem méritos sozinhas. Eu prefiro os ambientes onde as pessoas } \\
\text { trabalham": Sempre juntas; Às vezes juntas; ou Sempre sozinhas. }\end{array}$ \\
V5 & $\begin{array}{l}\text { "No ambiente de trabalho, entre abrir o jogo fornecendo informação } \\
\text { sempre que necessário ou omitir informação para auferir vantagem (tirar } \\
\text { proveito) eu procuro": Sempre abrir o jogo; Às vezes abrir o jogo, mas às } \\
\text { vezes omitir informação; ou Nunca abrir o jogo. }\end{array}$ \\
V7 & $\begin{array}{l}\text { "Para que o meu trabalho se sobressaia eu prefiro adotar uma atitude": } \\
\text { Competitiva, pois a organização pode se beneficiar; Igualmente } \\
\text { competitiva e cooperativa, independentemente das condições; ou } \\
\text { Cooperativa, pois a organização pode se beneficiar. }\end{array}$
\end{tabular}

\section{V8 "Para alcançar minhas metas eu me comporto de maneira": Sempre} cooperativa; $50 \%$ das vezes cooperativa e $50 \%$ competitiva; ou Sempre competitiva

V9 "Quando eu jogo com pessoas com as quais NÃO tenho uma relação de amizade, procuro tornar a disputa": Sempre acirrada (quero vencer sempre); Às vezes acirrada (procuro vencer, mas não esquento a cabeça): ou Nunca acirrada (não me importa vencer, vale a distração).

\section{V10 "Na faculdade, quando era necessário participar de atividades em grupo para a realização de trabalhos acadêmicos, eu: Compartilhava com os colegas todos os meus conhecimentos, sem restrições; Contribuía com a mesma intensidade que meus colegas; ou Só compartilhava meus conhecimentos desde que de isto me trouxesse algum benefício". \\ V14 "Em sua opinião, qual das afirmativas abaixo descreve a atitude mais adequada de uma pessoa que deseja alcançar sucesso profissional": 0 seu sucesso SEMPRE pressupõe o fracasso do outro; O seu sucesso não possui ligação com o do outro; ou O seu sucesso ÀS VEZES pressupõe 0 sucesso do outro.}

V17 "Se ganhar é sempre bom, para eu ganhar dos meus adversários eu devo": Jogar sempre COM os meus adversários; Às vezes COM os meus adversários, às vezes CONTRA eles; ou Jogar sempre CONTRA os meus adversários

V19 "Quando um amigo e eu nos juntamos para jogar CONTRA desconhecidos eu ajo de forma": Sempre acirrada (quero vencer sempre); Às vezes acirrada (procuro vencer, mas não esquento a cabeça); ou Nunca acirrada (não me importa vencer, vale a distração).

V20 "Quando um amigo e eu nos juntamos para jogar CONTRA desconhecidos eu ajo de forma": Sempre acirrada (quero vencer sempre); Às vezes acirrada (procuro vencer, mas não esquento a cabeça); ou Nunca acirrada (não me importa vencer, vale a distração).

V21 "As organizações estão incorporando novas formas de remuneração com vistas a atrair, reter e motivar seus colaboradores. Exemplo disto são os programas de remuneração variável. A alternativa que mais se aproxima da minha maneira de pensar quanto à composição ideal das metas para a implantação do sistema de recompensa deve ser": $100 \%$ metas coletivas, pois o sucesso deve ser resultado do trabalho de todos; $50 \%$ metas coletivas e $50 \%$ metas individuais; ou $100 \%$ individuais, pois quem contribui mais deve ter maior reconhecimento.

V22 "Na escolha de uma empresa para trabalhar, eu prefiro um ambiente onde a COMPETIÇÃO para a obtenção de resultados é": Fundamental; Importante; ou Não é importante.

FONTE: Dados da Pesquisa (2012)

\section{O modelo log-linear e as associações entre as variáveis (1,2 e 3)}

O modelo Log Linear, conforme mencionado, será utilizado para avaliar a possível associação entre as variáveis explicativas e cada variável resposta, pois permite avaliar diferentes tipos de associações entre mais de duas variáveis simultaneamente, quando essas são expressas por meio de escalas nominais ou ordinais.

Balassiano (2009) define cinco modelos hierárquicos de possíveis associações entre as três variáveis $(1,2$, e 3$)$ e respectivas notações: 


\section{Independência mútua entre as variáveis [1] [2] [3]}

Esse modelo, quando ajustado, representa a total falta de associação entre as trêws variáveis. Cada uma delas, no entanto, pode apresentar variações diferenciadas entre as categorias que as definem (efeito simples), independentemente das demais.

\section{Associação parcial [12] [3]}

Nesse modelo, as variáveis 1 e 2 são associadas, porém, ambas são independentes da terceira variável. Em outras palavras, as variáveis 1 e 2 são associadas em cada categoria da variável 3, apresentando a mesma razão de chances nas categorias daquela variável. Quando a variável 3 é a resposta, apenas o seu efeito simples será objeto de análise já que a associação entre variáveis explicativas não é o objeto do estudo.

\section{Independência Condicional [13] [23]}

Quando ajustado aos dados, esse modelo representa a independência das variáveis 1 e 2, para cada nível da variável 3 , podendo cada uma daquelas estar, ou não, associada à última. Em geral, a significância de efeitos interativos implica na significância dos efeitos simples entre as respectivas variáveis, mas não necessariamente.

\section{Modelo saturado [123]}

Esse modelo contempla todos os tipos de associações que podem existir entre as três variáveis. É conhecido como modelo saturado porque explica com exatidão as estruturas das células que representam uma tabela de tripla entrada. Como todos os possíveis efeitos estão presentes, esse modelo não apresenta resíduos e não pode ser testado estatisticamente pela incapacidade de ser refutado.

\section{Sem interação do $3^{\circ}$ Grau [12] [13] [23]}

Nesse modelo, a associação entre um par de variáveis, independente do par, é idêntica para qualquer nível da terceira variável. Nele podem ser visualizadas todas as associações duplas.

\section{Análise dos resultados}

\section{Perfil da amostra}

A amostra foi constituída pelos alunos dos cursos de pós-graduação da IES, usuários da rede social (Facebook), leitores de um blog de economia, funcionários do SEBRAE/ES e por ex-alunos e pessoas que compõem a rede de relacionamento da autora do trabalho. Os critérios de inclusão na amostra foram definidos com base nos objetivos estabelecidos para a pesquisa. A base de dados contou com 901 respondentes e possui as seguintes características:

Em termos de gênero, a amostra teve a participação de 467 respondentes do gênero feminino e de 434 respondentes do gênero masculino ( $51,8 \%$ e $48,2 \%$, respectivamente).

Do ponto de vista do status socioeconômico, no Gráfico 2, estabeleceu-se um corte em três níveis com base na renda familiar: (1) até $\mathrm{R} \$ 2.000,00$ com 252 participantes; (2) entre $R \$ 2.001,00$ e $R \$ 5.000,00$ com 446 participantes; e (3) acima de $\mathrm{R} \$ 5.000,00$ com 188 participantes, representando percentual de $28,4 \%, 50,3 \%$ e $21,2 \%$ da amostra, que é de 901 respondentes.

\section{Gráfico 1 - Classificação da amostra por geração e renda}

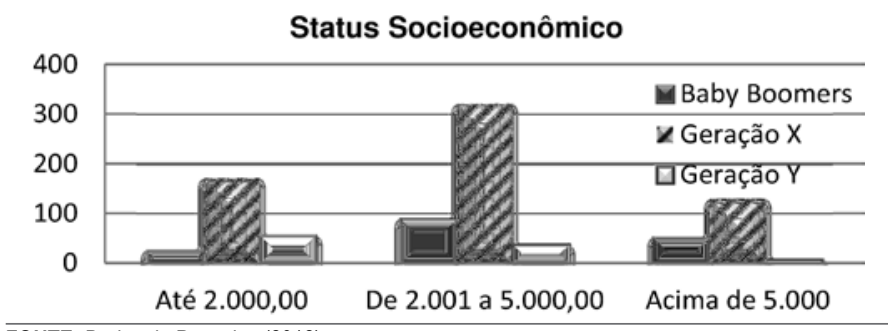

FONTE: Dados da Pesquisa (2012)

No que diz respeito ao hábito de jogar, foram considerados jogadores os participantes que disseram jogar pelo menos 4 horas por semana. Considerando-se as devidas proporções relacionadas ao número de respondentes de cada geração, conforme a Tabela 2, nota-se que a geração Y gasta mais tempo semanalmente com jogos eletrônicos, ou seja, de um total de 103 respondentes dessa geração, 19 dizem jogar mais do que 4 horas por semana, o que equivale a 18,4\%. Já a geração X, possui 60 respondentes que são considerados jogadores, de um total de 631, ou seja, 9,5\%.

Com 167 respondentes, uma frequência total superior à geração Y, os baby boomers possuem a menor frequência dos considerados jogadores, com um total de apenas 7, o que representa $4,2 \%$ do total. Constata-se também que não há frequência de jogadoras do sexo feminino da geração Y. Ou seja, proporcionalmente, a frequência é exclusivamente de jogadores do sexo masculino. Diferente da geração X, que apresenta uma frequência de 32 jogadores do sexo feminino, contra 28 jogadores do sexo masculino. Já na geração baby boomers houve ligeira superioridade dos respondentes jogadores do sexo masculino, com um total de 4, contra 3 respondentes do sexo feminino. Entretanto, quando se analisam as grandezas, percebe-se uma superioridade de 33,3\% dos jogadores do primeiro em relação ao segundo.

\section{Tabela 1 - Classificação da amostra por tempo médio de horas jogadas / gênero / geração}

\begin{tabular}{c|c|c|c|c|c|c|}
$\begin{array}{c}\text { Horas Semana } \\
\text { Jogadas } \\
\text { por } \\
\text { Semana }\end{array}$ & $\begin{array}{c}\text { Baby Boomers } \\
\text { (nascidos } \\
\text { até 1964) }\end{array}$ & $\begin{array}{c}\text { Geração X } \\
\text { (nascidos entre } \\
1965 \text { e 1977) }\end{array}$ & \multicolumn{2}{|c|}{$\begin{array}{c}\text { Geração Y } \\
\text { (nascidos a } \\
\text { partir de 1978) }\end{array}$} \\
\cline { 2 - 8 } & $\begin{array}{c}\text { Femi- } \\
\text { nino }\end{array}$ & $\begin{array}{c}\text { Mascu- } \\
\text { lino }\end{array}$ & $\begin{array}{c}\text { Femi- } \\
\text { nino }\end{array}$ & $\begin{array}{c}\text { Mascu- } \\
\text { lino }\end{array}$ & $\begin{array}{c}\text { Femi- } \\
\text { nino }\end{array}$ & $\begin{array}{c}\text { Mascu- } \\
\text { lino }\end{array}$ \\
\hline$<4 h$ & 24 & 15 & 69 & 99 & 10 & 17 \\
$\geq 4 h$ & 3 & 4 & 32 & 28 & 0 & 19 \\
\hline Não se aplica & 62 & 59 & 231 & 172 & 36 & 21 \\
\hline Total & 89 & 78 & 332 & 299 & 46 & 57 \\
\hline
\end{tabular}

FONTE: Dados da Pesquisa (2012)

A Tabela 3 apresenta as estatísticas referentes à quantidade de horas trabalhadas, por geração. Percebe-se que não houve ocorrência de jogadores que não estão inseridos no mercado de trabalho. Dentre os que trabalham ao menos 40 horas, 76,4\% correspondem aos jogadores da geração $X$. Ou seja, um percentual 7 vezes maior do que os jogadores da geração Y. Esta razão cai significativamente quando se trata do intervalo entre 20 e 40 horas semanais, que ainda apresenta a predominância da geração X, porém apenas 1,75 vezes maior em relação à geração Y. 


\section{Tabela 2 - Frequência dos jogadores referentes às horas trabalhadas}

\begin{tabular}{c|c|c|c|}
\hline Anos de estudo & Baby Boomers & Ceração X & Geração Y \\
\hline Até 20 horas & 5 & 22 & 10 \\
\hline Entre 20 e 40 horas & 43 & 156 & 25 \\
\hline 40 horas ou mais & 64 & 251 & 35 \\
\hline Não se aplica & 45 & 180 & 25 \\
\hline Total & 157 & 609 & 95 \\
\hline
\end{tabular}

FONTE: Dados da Pesquisa (2012)

\section{Os modelos ajustados}

A seguir são apresentadas as análises dos resultados pelos modelos ajustados aos dados. Dentre as quatorze variáveis iniciais, treze se ajustaram ao modelo de Associação parcial [12] [3]. Somente uma variável se ajustou ao modelo de Independência condicional [12] [23].

$\mathrm{O}$ modelo de associação parcial ajustado às variáveis $\mathrm{V} 1$, V3, V4, V5, V7, V8, V9, V10, V14, V17, V19, V21 e V22, foi:

$$
\ln _{i j k}=\mu+\lambda_{i}^{1}+\lambda_{j}^{2}+\lambda_{k}^{3}+\lambda_{i j}^{1 * 2}
$$

Onde:

$l n_{i j k}=L n$ dos valores esperados nas células $i j k$;

$\mu=$ média geral do $L n$ das frequências esperadas;

$\lambda_{i}^{1}=$ efeito da variável Sexo no nível $i$;

$\lambda_{j}^{2}=$ efeito da variável Hábito de Jogar no nível $j$;

$\lambda_{k}^{3}=$ efeito da variável de interesse (V1, [...], V22) no nível $k$; e

$\lambda_{i j}^{1 * 2}=$ efeito da interação de $2^{\mathrm{a}}$ ordem entre as variáveis sexo e hábito de jogar nos níveis $i j$.

Para a variável V20 o modelo de independência condicional ajustado foi:

$$
\ln _{i i k}=\mu+\lambda_{i}^{1}+\lambda_{i}^{2}+\lambda_{k}^{3}+\lambda_{i i}^{1 * 2}
$$

Onde

$l n_{i j k}=L n$ dos valores esperados nas células $i j k$;

$\mu=$ média geral do $L n$ das frequências esperadas;

$\lambda_{i}^{1}=$ efeito da variável Sexo no nível $i$;

$\lambda_{j}^{2}=$ efeito da variável Hábito de Jogar no nível $j$;

$\lambda_{k}^{3}=$ efeito da variável de interesse (V1, [...], V22) no nível $k$;

$\lambda_{i j}^{1 * 2}=$ efeito da interação de $2^{\mathrm{a}}$ ordem entre as variáveis sexo e hábito de jogar nas combinações dos níveis $i j$;

Como todos os modelos, as variáveis explanatórias "Sexo" e "Hábito de Jogar" são relacionadas entre si. Por isso, a relação entre elas não será representada. Somente na variável 20 o "hábito de jogar" não revelou ser significante. Porém, quando se analisa o "Sexo", todos os modelos apresentaram influência nessa variável.

Das quatorze variáveis que foram propostas neste estudo, uma não apresentou influência na relação "hábito de jogar" e "sexo": V22 ("Na escolha de uma empresa para trabalhar, eu prefiro um ambiente onde a competição para a obtenção de resultados é").

As tabelas a seguir demonstram os modelos ajustados, bem como as variáveis que apresentaram significância estatística, ou seja, as que não a obtiveram foram retiradas.

A Tabela 4 mostra os efeitos estimados para a variável 1 (V1), "O ambiente de trabalho é formado por diversas gerações que trazem consigo diferentes valores, habilidades técnicas e conhecimentos. Minimizar os efeitos dessas diferenças e formar equipes harmônicas que aumentam o desempenho (tanto individual quanto do grupo) tem sido um dos grandes desafios enfrentados pelas organizações. "Entre colaborar com os colegas para todos ganharem ou não colaborar para que meu trabalho se sobressaia, eu prefiro colaborar".

\section{Tabela 4 - efeitos estimados para variável v1}

\begin{tabular}{|l|c|c|c|c|}
\hline Parâmetro & Estimativa & Erro Padrão & P-valor & Razäo de Chances \\
\hline Constante & 1.22 & 0.34 & 0.00 & 3.40 \\
\hline$[G=1]$ & -1.36 & 0.37 & 0.00 & 0.26 \\
\hline $\mathrm{J}=0]$ & -0.46 & 0.27 & 0.09 & 0.63 \\
\hline $\mathrm{V} 1=1]$ & 2.03 & 0.34 & 0.00 & 7.60 \\
\hline
\end{tabular}

FONTE: Dados da Pesquisa (2012)

Para a geração Y, a colaboração com os colegas é predominante, isto é, pode-se afirmar que a maioria dos respondentes dessa geração prefere colaborar a competir, e isso corresponde a 7,6 vezes () mais do que aquele que não prefere colaborar, ou prefere somente colaborar em $50 \%$ das vezes.

A Tabela 5 mostra os efeitos estimados para a variável 3 (V3), "Na escolha de uma empresa para trabalhar, eu prefiro um ambiente onde a COLABORAÇÃO para a obtenção de resultados é: Fundamental; Importante; ou Irrelevante".

Tabela 5 - efeitos estimados para variável v3

\begin{tabular}{|l|c|c|c|c|}
\hline Parâmetro & Estimativa & Erro Padrão & P-valor & Razão de Chances \\
\hline Constante & 0.02 & 0.59 & 0.97 & 1.02 \\
\hline$[G=1]$ & -1.36 & 0.37 & 0.00 & 0.26 \\
\hline$[J=0]$ & -0.46 & 0.27 & 0.09 & 0.63 \\
\hline$[\mathrm{V} 3=1]$ & 3.36 & 0.59 & 0.00 & 28.67 \\
\hline $\mathrm{V} 3=2]$ & 1.54 & 0.64 & 0.02 & 4.67 \\
\hline
\end{tabular}

FONTE: Dados da Pesquisa (2012)

Para essa variável, a geração Y revela que é de fundamental importância colaborar com a obtenção dos resultados, e isso significa, em termos de razão de chances, que eles consideram "fundamental" 29 vezes a mais que para aqueles que consideram apenas "importante" ou não o consideram. Já os que acham apenas "importante", demonstram ser aproximadamente 5 vezes maior que os que não o acham.

Na Tabela 6 são demonstrados os efeitos estimados para a variável 4 (V4), "O mercado de trabalho pode ter ambientes que variam entre aqueles em que as pessoas trabalham juntas, para que todos ganhem méritos iguais, ou aqueles onde as pessoas preferem trabalhar individualmente, para ganharem méritos sozinhas. Eu prefiro os ambientes onde as pessoas trabalham: Sempre juntas; Às vezes juntas; ou Sempre sozinhas".

Quando se analisa o ambiente de trabalho, onde as pessoas trabalham juntas, o modelo mostra que, em $50 \%$ das vezes, é melhor trabalhar dessa forma. E 8 vezes maior, para os que acham que esta percentagem é válida, quando avaliada em relação aos que preferem trabalhar sempre sozinhos.

A Tabela 7 demonstra os efeitos estimados para a variável 5 (V5), "No ambiente de trabalho, entre abrir o jogo fornecendo informação sempre que necessário ou omitir informação para auferir vantagem (tirar proveito) eu procuro: Sempre abrir o jogo; Às vezes abrir o jogo, mas às vezes omitir informação; ou Nunca abrir o jogo". 
Tabela 6 - Efeitos estimados para variável v4

\begin{tabular}{l|c|c|c|c}
\hline Parâmetro & Estimativa & Erro Padrẽo & P-valor & Razão de Chances \\
\hline Constante & -0.39 & 0.72 & 0.59 & 0.68 \\
\hline$[\mathrm{G}=1]$ & -1.36 & 0.37 & 0.00 & 0.26 \\
\hline $\mathrm{J}=0]$ & -0.46 & 0.27 & 0.09 & 0.63 \\
\hline$[\mathrm{V} 4=1]$ & 3.75 & 0.72 & 0.00 & 42.50 \\
\hline$[\mathrm{V} 4=2]$ & 2.08 & 0.75 & 0.01 & 8.00 \\
\hline
\end{tabular}

FONTE: Dados da Pesquisa (2012)

Tabela 7 - Efeitos estimados para variável v5

\begin{tabular}{l|c|c|c|c} 
Parâmetro & Estimativa & Erro Padräo & P-valor & Retäo de Chances \\
\hline Constante & -0.39 & 0.72 & 0.59 & 0.68 \\
\hline $\mathrm{G}=1]$ & -1.36 & 0.37 & 0.00 & 0.26 \\
{$[\mathrm{~J}=0]$} & -0.46 & 0.27 & 0.09 & 0.63 \\
\hline $\mathrm{V} 5=1]$ & 3.80 & 0.72 & 0.00 & 44.50 \\
\hline $\mathrm{V} 5=2]$ & 1.79 & 0.76 & 0.02 & 6.00 \\
\hline
\end{tabular}

FONTE: Dados da Pesquisa (2012).

A geração Y é mais adepta a abrir o jogo fornecendo informação em cerca de 44 vezes a mais do que aquelas que abrem às vezes. Esses, por sua vez, também se mostraram significantes ao nível de $5 \%$, ou seja, para a geração Y, fornecer informação às vezes é mais relevante do que a aqueles que quase nunca a fornecem.

Demonstram-se na Tabela 8 os efeitos estimados para a variável 7 (V7), "Para que o meu trabalho se sobressaia eu prefiro adotar uma atitude: Competitiva, pois a organização pode se beneficiar; Igualmente competitiva e cooperativa, independentemente das condições; ou Cooperativa, pois a organização pode se beneficiar".

Tabela 8 - Efeitos estimados para variável v7

\begin{tabular}{|l|c|c|c|c|}
\hline Parâmetro & Estimativa & Erro Padrão & P-valor & Razto de Chances \\
\hline Constante & 2.58 & 0.21 & 0.00 & 13.25 \\
\hline$[G=1]$ & -1.36 & 0.37 & 0.00 & 0.26 \\
\hline $\mathrm{J}=0]$ & -0.46 & 0.27 & 0.09 & 0.63 \\
\hline $\mathrm{V} 7=1]$ & -0.57 & 0.27 & 0.03 & 0.56 \\
\hline
\end{tabular}

FONTE: Dados da Pesquisa (2012)

Os respondentes da geração Y preferem adotar o comportamento competitivo para que o seu trabalho se sobressaia. Entretanto, quando é comparada com o comportamento de igualdade competitiva e cooperativa, a geração Y revela ser 0.56 vezes menor.

A Tabela 9 demonstra os valores estimados para a variável 8 (V8), "Para alcançar minhas metas eu me comporto de maneira: Sempre cooperativa; $50 \%$ das vezes cooperativa e $50 \%$ competitiva; ou Sempre competitiva".

O modelo Log Linear proposto mostra que os respondentes preferem se comportar de maneira cooperativa para alcançar os seus objetivos. Outro aspecto a se ressaltar é a preferência em se comportar de maneira competitiva ou das duas formas (coope- rativa e competitiva). Esses são 4,5 vezes superiores em relação aos que preferem adotar um comportamento sempre competitivo.

Tabela 9 - Efeitos estimados para variável v8

\begin{tabular}{|l|c|c|c|c|}
\hline Parâmetro & Estimativa & Erro Padrão & P-valor & Razăo de Chances \\
\hline Constante & 0.31 & 0.52 & 0.55 & 1.36 \\
\hline$[G=1]$ & -1.36 & 0.37 & 0.00 & 0.26 \\
\hline$[J=0]$ & -0.46 & 0.27 & 0.09 & 0.63 \\
\hline$[V 8=1]$ & 3.01 & 0.51 & 0.00 & 20.25 \\
\hline$[V 8=2]$ & 1.50 & 0.55 & 0.07 & 4.50 \\
\hline
\end{tabular}

FONTE: Dados da Pesquisa (2012)

A Tabela 10, por sua vez, traz os efeitos estimados para a variável 8 (V8), “Quando eu jogo com pessoas com as quais NÃO tenho uma relação de amizade, procuro tornar a disputa: Sempre acirrada (quero vencer sempre); Às vezes acirrada (procuro vencer, mas não esquento a cabeça); ou Nunca acirrada (não me importa vencer, vale a distração)".

Tabela 10 - Efeitos estimados para variável v9

\begin{tabular}{l|c|c|c|c}
\hline Parâmetro & Estimativa & Erro Padrão & P-valor & Razäo de Chances \\
\hline Constante & 1.87 & 0.27 & 0.00 & 6.46 \\
\hline$G=1]$ & -1.36 & 0.37 & 0.00 & 0.26 \\
\hline $\mathrm{J}=0]-0.46$ & 0.27 & 0.00 & 0.63 & \\
\hline $\mathrm{V} 9=1]$ & 0.82 & 0.28 & 0.00 & 2.26 \\
\hline $\mathrm{V} 9=2]$ & 0.77 & 0.28 & 0.00 & 2.16 \\
\hline
\end{tabular}

Fonte: Dados da Pesquisa (2012)

Quando se analisa a disputa no jogo com pessoas que não se conhecem, o modelo revela que a geração $\mathrm{Y}$ é bem dividida em relação a ser "sempre acirrada" e "às vezes" mostrando que essa geração é bem competitiva e gosta de vencer, mas sem que precise se preocupar muito.

$\mathrm{Na}$ Tabela 11 demonstram-se os efeitos estimados para a variável 10 (V10), "Na faculdade, quando era necessário participar de atividades em grupo para a realização de trabalhos acadêmicos, eu: Compartilhava com os colegas todos os meus conhecimentos, sem restrições; Contribuía com a mesma intensidade que meus colegas; ou Só compartilhava meus conhecimentos se me trouxesse algum benefício".

\section{Tabela 11 - Efeitos estimados para variável v10}

\begin{tabular}{|l|c|c|c|c|}
\hline Parâmetro & Estimativa & Erro Padrăo & P-valor & Rapajo de Chances \\
\hline Constante & 1.87 & 0.27 & 0.00 & 6.46 \\
\hline$[G=1]$ & -1.36 & 0.37 & 0.00 & 0.26 \\
\hline$[J=0]$ & -0.46 & 0.27 & 0.00 & 0.63 \\
\hline$[\mathrm{V} 9=1]$ & 0.82 & 0.28 & 0.00 & 2.26 \\
\hline$[\mathrm{V} 9=2]$ & 0.77 & 0.28 & 0.00 & 2.16 \\
\hline
\end{tabular}

FONTE: Dados da Pesquisa (2012)

Quando era necessário participar de atividades em grupo, os respondentes afirmaram que compartilhavam na maioria das vezes os seus conhecimentos com os colegas, mostrando que esses 
são solidários e não egoístas, mas também demandavam de informações dos mesmos para a realização dos trabalhos acadêmicos.

A Tabela 12 mostra os efeitos estimados para a variável 14 (V14), "Em sua opinião, qual das afirmativas abaixo descreve a atitude mais adequada de uma pessoa que deseja alcançar sucesso profissional: O seu sucesso SEMPRE pressupõe o fracasso do outro; O seu sucesso não possui ligação com o do outro; ou $\mathrm{O}$ seu sucesso ÀS VEZES pressupõe o sucesso do outro”.

Tabela 12 - Efeitos estimados para variável v14

\begin{tabular}{l|c|c|c|c|}
\hline Parâmetro & Estimativa & Erro Padräo & P-valor & Razäo de Chances \\
\hline Constante & 2.66 & 0.21 & 0.00 & 14.27 \\
\hline$[\mathrm{G}=1]$ & -1.36 & 0.37 & 0.00 & 0.26 \\
\hline $\mathrm{J}=0]$ & -0.46 & 0.27 & 0.09 & 0.63 \\
\hline $\mathrm{V} 14=1]$ & -0.48 & 0.25 & 0.04 & 0.62 \\
\hline
\end{tabular}

FONTE: Dados da Pesquisa (2012)

De acordo com a amostra desta pesquisa, o sucesso às vezes pressupõe o fracasso do outro em 0.6 vezes menos que os respondentes que acham que o sucesso não possui ligação com o outro, pela indicação desses para a obtenção de sucesso profissional.

A Tabela 13 demonstra os efeitos estimados para a variável 17 (V17), "Se ganhar é sempre bom, para eu ganhar dos meus adversários eu devo": Jogar sempre COM os meus adversários; Às vezes COM os meus adversários, às vezes CONTRA eles; ou Jogar sempre CONTRA os meus adversários.

Tabela 13 - Efeitos estimados para variável v17

\begin{tabular}{l|c|c|c|c|}
\hline Parêmetro & Estimativa & Erro Padrão & P-valor & Razão de Chances \\
\hline Constante & 0.02 & 0.59 & 0.97 & 1.02 \\
\hline $\mathrm{G}=1]$ & -1.36 & 0.37 & 0.00 & 0.26 \\
{$[\mathrm{~J}=0]$} & -0.46 & 0.27 & 0.09 & 0.63 \\
\hline $\mathrm{V} 3=1]$ & 3.36 & 0.59 & 0.00 & 28.67 \\
\hline $\mathrm{V} 3=2]$ & 1.54 & 0.64 & 0.02 & 4.67 \\
\hline
\end{tabular}

FONTE: Dados da Pesquisa (2012)

As afirmativas jogar, a maioria das vezes e às vezes, com os meus adversários, são 2,3 vezes maiores do que jogar às vezes com e contra os meus adversários. Assim, a amostra também revela que, os que acham que ganhar é sempre bom, mas para isso ele deve jogar às vezes com e contra, são mais frequentes que para aqueles que gostam de jogar sempre ou quase sempre contra.

A Tabela 14 demonstra os efeitos estimados para a variável 19 (V19), “Quando eu jogo CONTRA um amigo, para vencê-lo eu adoto uma estratégia: Sempre acirrada (quero vencer sempre); Às vezes acirrada (procuro vencer, mas não esquento a cabeça); ou Nunca acirrada (não me importa vencer, vale a distração)”.

Para a geração Y, quando se joga contra um amigo, para vencê-lo, adotam a estratégia de serem frequentemente ou sempre competitivos. Porém, às vezes, ser competitivo é mais significante que para aqueles que raramente ou nunca o são.

$\mathrm{Na}$ Tabela 15 demonstram-se os efeitos estimados para a variável 20 (V20), “Quando um amigo e eu nos juntamos para jogar CONTRA desconhecidos eu ajo de forma”: Sempre acirrada (quero vencer sempre); Às vezes acirrada (procuro vencer, mas não esquento a cabeça); ou Nunca acirrada (não me importa vencer, vale a distração).

Tabela 14 - Efeitos estimados para variável v19

\begin{tabular}{l|c|c|c|c|}
\hline Parâmetro & Estimativa & Erro Padrăo & P-valor & Razajo de Chances \\
\hline Constante & 1.87 & 0.27 & 0.00 & 6.46 \\
\hline$[G=1]$ & -1.36 & 0.37 & 0.00 & 0.26 \\
\hline$[J=0]$ & -0.46 & 0.27 & 0.09 & 0.63 \\
\hline$[V 19=1]$ & 0.99 & 0.27 & 0.00 & 2.68 \\
\hline$[V 19=2]$ & 0.55 & 0.29 & 0.06 & 1.74 \\
\hline
\end{tabular}

FONTE: Dados da Pesquisa (2012)

Tabela 15 - Efeitos estimados para variável v20

\begin{tabular}{l|c|c|c|c}
\hline Parâmetro & Estimativa & Erro Padrễo & P-valor & Razäo de Chances \\
\hline Constante & 0.46 & 0.71 & 0.51 & 1.59 \\
\hline$[G=1]$ & -1.36 & 0.37 & 0.00 & 0.26 \\
\hline$[J=0]$ & 1.03 & 0.79 & 0.19 & 2.81 \\
\hline$[V 20=1]^{*}[J=0]$ & 0.98 & 0.34 & 0.00 & 2.67 \\
\hline$[\mathrm{V} 20=1]^{*}[J=1]$ & 2.80 & 0.73 & 0.00 & 16.50 \\
\hline$[\mathrm{V} 20=2]^{*}[J=1]$ & 1.50 & 0.78 & 0.05 & 4.50 \\
\hline$[G=1]^{*}[J=0]$ & 1878 & 0.461 & 0.00 & 6.54 \\
\hline
\end{tabular}

FONTE: Dados da Pesquisa (2012)

Para os respondentes que jogam com um amigo, contra uma pessoa desconhecida, há uma associação com o hábito de jogar e não jogar. Para os que não têm o hábito de jogar jogos eletrônicos, ser sempre ou frequentemente competitivo é 2,7 vezes maior que para aqueles que raramente ou nunca são competitivos. Essa observação se corrobora para os que têm o costume de jogar com maior frequência, que é 16,5 vezes maior.

Para os jogadores que são às vezes competitivos e não procuram vencer, a amostra revelou uma frequência de 4,5 vezes a mais dos que não são ou raramente são competitivos.

A Tabela 16, por sua vez, demonstra os efeitos estimados para a variável 21 (V21), “As organizações estão incorporando novas formas de remuneração com vistas a atrair, reter e motivar seus colaboradores. Exemplo disto são os programas de remuneração variável. A alternativa que mais se aproxima da minha maneira de pensar quanto à composição ideal das metas para a implantação do sistema de recompensa deve ser: $100 \%$ metas coletivas, pois o sucesso deve ser resultado do trabalho de todos; $50 \%$ metas coletivas e $50 \%$ metas individuais; ou $100 \%$ individuais, pois quem contribui mais deve ter maior reconhecimento".

Tabela 16 - efeitos estimados para variável v21

\begin{tabular}{|l|c|c|c|c|}
\hline Parâmetro & Estimativa & Erro Padrăo & P-valor & Razajo de Chances \\
\hline Constante & 1.49 & 0.31 & 0.00 & 4.42 \\
\hline$[G=1]$ & -1.36 & 0.37 & 0.00 & 0.26 \\
\hline$[J=0]$ & -0.46 & 0.27 & 0.09 & 0.63 \\
\hline$[\mathrm{V} 21=1]$ & 1.50 & 0.31 & 0.00 & 4.46 \\
\hline$[\mathrm{V} 21=2]$ & 0.90 & 0.33 & 0.01 & 2.46 \\
\hline
\end{tabular}

FONTE: Dados da Pesquisa (2012) 
Quando se avalia a maneira de pensar quanto à composição ideal das metas para implantação do sistema de recompensas, os respondentes acham que a maioria das metas devem ser coletivas, pois o sucesso deve ser resultado do trabalho de todos. Para a meta de $50 \%$ coletiva e $50 \%$ individual, a amostra é significativa também, revelando-se 2,5 vezes maiores em relação aos que acham que as metas devem ser individuais.

\section{Discussão dos resultados}

Ao longo do desenvolvimento do trabalho foram abordados aspectos relacionados ao comportamento cooperativo ou competitivo da geração Y, como forma de entender as possíveis peculiaridades desencadeadas pelos jogos eletrônicos nessa geração, que possui características que a diferencia de outras gerações.

A variável V1 ("Entre colaborar com os colegas para todos ganharem ou não colaborar para que meu trabalho se sobressaia, eu prefiro colaborar') revela que, para a geração Y a colaboração com os colegas é predominante, pode-se afirmar que a maioria dos respondentes desta geração prefere colaborar a competir, sendo que, para Nunes (2004) a cultura da cooperação é uma filosofia baseada em conceitos e valores humanísticos como solidariedade, confiança e organização funcional de grupos, tendo como propósito substituir o individualismo pela ação coletiva.

Deutsch (1973) aponta que membros de grupos cooperativos terão mais facilidade que membros de grupos competitivos em valorizar as ações dos companheiros conducentes aos objetivos destes. Tal comportamento pode ser constatado pela variável V3 ("Na escolha de uma empresa para trabalhar, eu prefiro um ambiente onde a colaboração para a obtenção de resultados é”) deixando evidente que para a geração Y é de fundamental importância colaborar com a obtenção dos resultados.

Outra característica cooperativa constatada na geração $\mathrm{Y}$ que pode ser corroborada por Deutsch (1973) é a sua capacidade de ajuda mútua, pois, em um ambiente onde as pessoas trabalham juntas (variável V4) os mesmos demonstraram compartilhar e demandar conhecimentos com seus colegas.

Na variável V5 ("No ambiente de trabalho, entre abrir o jogo fornecendo informação sempre que necessário ou omitir informação para auferir vantagem, eu procuro") a geração Y se mostrou mais adepta a abrir o jogo fornecendo informação em cerca de 44 vezes a mais do que aquelas que abrem às vezes. Para Deutsch (1973), na Teoria da Interdependência Social, a intercomunicação de ideias, a coordenação de esforços, a amizade e o orgulho por pertencer ao grupo são fundamentais para a harmonia e a eficácia do grupo.

A variável V7 ("Para que o meu trabalho se sobressaia eu prefiro adotar uma atitude") revela que os respondentes da geração Y preferem adotar o comportamento competitivo para que o seu trabalho se sobressaia. Entretanto, quando é comparada com o comportamento de igualdade competitiva e cooperativa, a geração Y revela ser 0.56 vezes menor. De fato, para Deutsch (1973) poucas são as situações na vida real que se caracterizam por serem puramente cooperativas ou puramente competitivas, sendo que certos aspectos cooperativos parecem desaparecer, quando seus membros se veem na situação de competir para a obtenção de objetivos mutuamente exclusivos.

$\mathrm{Na}$ variável V8 ("Para alcançar minhas metas eu me comporto de maneira") o modelo proposto mostra que os respondentes preferem se comportar de maneira cooperativa para alcançar os seus objetivos. Outro aspecto a se ressaltar é a preferência em se comportar de maneira competitiva ou das duas formas (cooperativa e competitiva). Brotto (1999) afirma que, cooperação e competição são processos distintos, porém, não muito distantes. As fronteiras entre eles são tênues, permitindo certo intercâmbio de características, de maneira que se pode encontrar em algumas ocasiões, uma competição-cooperativa e em outras, uma cooperação-competitiva.

Quando se analisa a disputa no jogo com pessoas que não se conhecem, na V9 ("Quando eu jogo com pessoas com as quais NÃO tenho uma relação de amizade, procuro tornar a disputa") o modelo revela que a geração Y é bem dividida em relação a ser "sempre acirrada" e "às vezes" mostrando que essa geração é bem competitiva e gosta de vencer. Nos mercados contemporâneos, sinais competitivos podem ser considerados elementos positivos quando o ambiente demandar esse tipo específico de comportamento para o sucesso de um empreendimento (ROBBINS, 2011).

A variável V10 ("Na faculdade, quando era necessário participar de atividades em grupo para a realização de trabalhos acadêmicos, eu") revela que, quando era necessário participar de atividades em grupo, os respondentes afirmaram que compartilhavam na maioria das vezes os seus conhecimentos com os colegas, mostrando que esses são solidários e não egoístas, mas também demandavam de informações dos mesmos para a realização dos trabalhos acadêmicos. Conforme define Brotto (1999) fica caracterizada uma situação cooperativa em que a ajuda mútua é frequente, sendo mais sensíveis às solicitações dos outros.

De acordo com a amostra, na variável V14 ("Em sua opinião, qual das afirmativas abaixo descreve a atitude mais adequada de uma pessoa que deseja alcançar sucesso profissional") o sucesso às vezes pressupõe o fracasso do outro em 0.6 vezes menos que os respondentes que acham que o sucesso não possui ligação com o outro. Para Lombardia, Stein e Pin (2008) a geração Y é vista como uma geração de resultados, não processos; para eles o importante é saber o que está acontecendo agora e reagir rapidamente.

A variável V17 ("Se ganhar é sempre bom, para eu ganhar dos meus adversários eu devo") aponta que, as afirmativas jogar, a maioria das vezes e às vezes, com os meus adversários, são 2,3 vezes maiores do que jogar às vezes com e contra os meus adversários. Assim, a amostra também revela que, os que acham que ganhar é sempre bom, mas para isso ele deve jogar às vezes com e contra, são mais frequentes que para aqueles que gostam de jogar sempre ou quase sempre contra. Para Balassiano (2009) algumas características dos jogos refletem as mesmas situações presentes na rotina diária de qualquer coordenador, gerente ou executivo de uma empresa: a) situações que demandam respostas rápidas dos jogadores; b) capacidade de análise dos riscos envolvidos em tais decisões; c) formas de aprendizado baseadas em tentativa-e-erro; d) circunstâncias em que muitas decisões devem ser tomadas rapidamente, exigindo total imersão em dados; e em diferentes modos de cooperar, competir e se relacionar com outras pessoas (em ambientes físicos ou virtuais).

Para a geração Y, quando se joga contra um amigo, para vencê-lo, adotam a estratégia de serem frequentemente ou sempre competitivos, conforme revela a variável V19 ("Quando eu jogo CONTRA um amigo, para vencê-lo eu adoto uma estratégia”). Porém, às vezes, ser competitivo é mais significante que para aqueles que raramente ou nunca o são. Para Deutsch (1973) situações competitivas apontam-se como positivas quando permitem a prevenção à estagnação de uma relação, dá estímulo a novos interesses e à curiosidade, bem como explora a capacidade de cada indivíduo. 
A variável V20 (“Quando um amigo e eu nos juntamos para jogar CONTRA desconhecidos eu ajo de forma") revela que, para os respondentes que jogam com um amigo, contra uma pessoa desconhecida, há uma associação com o hábito de jogar e não jogar. Para os que não têm o hábito de jogar jogos eletrônicos, ser sempre ou frequentemente competitivo é 2,7 vezes maior que para aqueles que raramente ou nunca são competitivos. Essa observação se corrobora para os que têm o costume de jogar com maior frequência, que é 16,5 vezes maior. Morais e Assis (2008) consideram que os jogos eletrônicos podem ser analisados como parte de um conjunto da produção cultural de uma sociedade, permitindo assim o entendimento de comportamentos e ideias compartilhadas pelos que estão imersos nesta realidade virtual, ou seja, os jogadores.

Na variável V21 quando se avalia a maneira de pensar quanto à composição ideal das metas para implantação do sistema de recompensas, os respondentes acham que a maioria das metas deve ser coletiva, pois o sucesso deve ser resultado do trabalho de todos. Para a meta de $50 \%$ coletiva e $50 \%$ individual, a amostra é significativa também, revelando-se 2,5 vezes maiores em relação aos que acham que as metas devem ser individuais. Ressalta-se que, os grupos são "todos dinâmicos" nos quais uma mudança na condição de algum membro ou de algum subgrupo muda a condição dos outros membros ou de outros subgrupos (JOHNSON et al., 1998).

\section{Considerações finais}

Analisar o impacto dos jogos eletrônicos na propensão da geração $\mathrm{Y}$ à cooperação ou competição no ambiente corporativo, à luz da teoria da interdependência social de Deustch (1973) foi o principal propósito deste estudo. Para isso, foram testadas duas hipóteses a respeito dos construtos hábito de jogar, cooperação e competição.

Ao longo do desenvolvimento do trabalho, foram abordados aspectos relacionados ao comportamento cooperativo ou competitivo da geração Y, como forma de entender as possíveis peculiaridades desencadeadas pelos jogos eletrônicos nessa geração, que possui características que a diferencia de outras gerações.

A partir da análise do contato da geração Y com o virtual, através do seu comportamento no jogo, foi possível constatar o importante papel que a tecnologia desempenhou na formação desses jovens, influenciando seu cotidiano e sendo uma aliada, diferente da visão de gerações anteriores.

Há reflexo de certas características dos jogos em situações reais do ambiente corporativo, pois os "jogadores" estão expostos a circunstâncias que necessitam de capacidade de análise, decisões rápidas, momentos cooperativos e competitivos, dentre outros.

Como contribuição para a Teoria da Interdependência Social, o estudo corrobora que a competição pode ser positiva em alguns momentos, pois sinais competitivos podem ser considerados elementos positivos quando o ambiente demandar este tipo específico de comportamento para o sucesso de um empreendimento. Aponta ainda que, a cooperação, processo social fundamental no contexto organizacional, é tida como importante pelo grupo geracional estudado.

Assim, o comportamento cooperativo, com base nas respostas apresentadas, mostrou-se de acordo com a hipótese levantada (H0), ou seja, os jogos eletrônicos influenciam jogadores da geração Y a maior propensão a cooperar, levantando a possibilidade de se confirmar que há predisposição maior para cooperar do que para competir.
Como limitação, aponta-se o fato de que pela amostra, não é possível generalizar para toda a geração $\mathrm{Y}$, pois a pesquisa não teve a abrangência necessária.

Para pesquisas futuras sugere-se uma análise qualitativa do conteúdo, do enredo dos jogos eletrônicos mais populares, a partir da literatura sobre jogos e práticas de gestão de pessoas, envolvendo a administração e a psicologia, analisando de que forma as empresas se beneficiam desses resultados.

O estudo também traz implicações práticas para os gestores, pois aponta que existe uma cultura de colaboração da geração Y, portanto, recomenda-se que esse conhecimento seja usado quando se selecionam profissionais, como critério adicional, podendo ser inserido na formação de equipes e em treinamentos.

\section{Referências}

ABDALLA, Maurício O princípio da cooperação: em busca de uma nova racionalidade. São Paulo: Paulus, 2002.

ALVES, Lynn Rosalina Gama. Game over: jogos eletrônicos e violência. 2004. 249f. Tese (Doutorado em Educação) - Universidade Federal da Bahia - UFBA, Salvador, 2004. Disponível em: http://www.lynn.pro. br/admin/files/lyn_artigo/685ef5af57.pdf. Acesso em: 26 ago. 2012.

BALASSIANO, Moisés. Relatório de projeto de pesquisa: jogos eletrônicos e o mercado de trabalho. Núcleo de estudos e carreiras, 2009.

BECK, John C.; WADE, Mitchell. Got game: how the gamer generation is reshaping business forever. Boston: Harvard Business School Press, 2004.

BENDASSOLLI, Pedro Fernando. O vocabulário da habilidade e da competência: algumas considerações neopragmáticas. Cadernos de Psicologia Social do Trabalho, São Paulo, v. 3-4, p. 65-76, 2001. Disponível em: http://www.revistasusp.sibi.usp.br/pdf/cpst/v3-4/v3-4a05.pdf. Acesso em: 26 ago. 2012.

BIAGIONI, Daniel. O emprego dos modelos log-lineares para análise de dados categóricos. Encontro Nacional de Pós-Graduação em Demografia e Áreas Afins. ABEP. Instituto de Filosofia e Ciências Humanas/ Unicamp, fev., 2010.

BROTTO, Fábio Otuzi. Jogos cooperativos: o jogo e o esporte como um exercício de convivência. 1999. 197f. Dissertação (Mestrado em Educação) - Universidade Estadual de Campinas - UEC, Campinas, 1999. Disponível em: http://www.aprendizagemsignificativa.com.br/artigos/jogos_cooperativos_original.pdf. Acesso em: 22 ago. 2012.

CHEN, Chao C.; CHEN, Xiao-Ping; MEINDL, James R. How can cooperation be fostered? The cultural effects of individualism-collectivism. The Academy of Management Review, v. 23, n. 2, p. 285-304 abr.1998. Disponível em: http://www.jstor.org/stable/259375. Acesso em: 29 ago. 2012

CHIUZI, Rafael Marcus; PEIXOTO, Bruna Ribeiro Gonçalves; FUSARI, Giovanna Lorenzini. Conflito de gerações nas organizações: um fenômeno social interpretado a partir da teoria de Erik Erikson. Temas psicol., Ribeirão Preto, v. 19, n. 2, dez. 2011 . Disponível em: http:// pepsic.bvsalud.org/scielo.php?script=sci_arttext\&pid=S1413-389X2 011000200018\&lng=pt\&nrm=iso. Acesso em 30 ago. 2012.

CORDEIRO, Gauss Moutinho.; DEMÉTRIO, Clarice Garcia Borges. Modelos Lineares Generalizados e Extensões. Disponível em: http:// www4.esalq.usp.br/departamentos/lce/arquivos/aulas/2010/LCE5868/ livro.pdf. Acesso em: 29 ago. 2012.

CRUMPACKER, Marta; CRUMPACKER, Jill Martha. Succession planning and generational stereotypes: Should HR consider age-based values and attitudes a relevant factor or a passing fad? Public Personnel Management, v. 36, n. 4, p. 349-369 winter 2007. Disponível em: http://hoosonline.virginia.edu/atf/cf/\%7Bbda77a21-0229-499a-ae10- 
eadbe96789d6\%7D/SUCCESSION\%20PLANNING GENERATIONAL. PDF. Acesso em: 29 ago. 2012.

DeFALCO, Alessandra. Jogos eletrônicos: do real ao virtual e vice-versa. Inovação Uniemp, Campinas, v. 3, n. 3, jun. 2007. Disponível em: http://inovacao.scielo.br/scielo.php?script=sci arttext\&pid=S1808$-23942007000300025 \& \operatorname{lng}=\mathrm{es} \& n r m=$ iso. Acesso em: 17 jun. 2012.

DeMARCO, Michael, LESSER, Eric; O’DRISCOLL, Tony. Leadership in a distributed world. Lessons from online gaming. IBM Institute for Business Value, 2007.

DENCKER, John C., JOSHI, Aparna; MARTOCCHIO, Joseph Joe. Employee benefits as a context for intergenerational conflict. Human Resource Management Review, v. 17, n. 2, p. 208-220, 2007. Disponível em: http://www.progep.org.br/MelhoresEmpresas/InfoDocs/ GPR397\%20-\%20Rodrigo\%20-\%20Gera\%C3\%A7\%C3\%B5es \%20 e\%20Carreiras.pdf. Acesso em:26 ago. 2012.

DEUTSCH, Morton. The resolution of conflict: constructive and destructive processes. New Haven and London: Yale University Press, 1973. Pp. 1-32; 349-400.

. A Theory of Cooperation and Competition. Human Relations, v.2, n. 2, p. 129-152 abr. 1949. Disponível em: http://hum.sagepub. com/content/2/2/129. Acesso em: 26 ago. 2012.

DeVELLIS, Robert F. Scale development: theory and applications. $2^{\text {a }}$ ed. Thousands Oacks: Sage Publications, 2003. Disponível em: http:// books.google.com.br/books?id=BYGxL6xLokUC\&printsec $=$ frontco ver $\& \mathrm{hl}=\mathrm{pt}-\mathrm{BR} \&$ source $=\mathrm{gbs}$ ge_summary_r\&cad $=0 \# \mathrm{v}=$ onepage $\& \mathrm{q} \&$ $\mathrm{f}=$ false. Acesso em: 22 ago. $20 \overline{12}$.

FEIXA, Carles; LECCARDI, Carmem. O conceito de geração nas teorias sobre juventude. Sociedade e Estado, Brasília, v. 25, n. 2, Aug. 2010. Disponível em: http://www.scielo.br/scielo.php?script=sci arttext\&pid=S0102-69922010000200003\&lng=en\&nrm=iso. Acesso em: 30 Ago. 2012.

FERREIRA, Fernanda Andrade Ramos. A influência dos jogos eletrônicos e do gênero sobre o comportamento social dos jovens da geração Y. 2010. 76f. Dissertação (Mestrado em Administração) - Fundação Getúlio Vargas - FGV, Rio de Janeiro, 2010. Disponível em: http:// bibliotecadigital.fgv.br/dspace/handle/10438/6574?show=full. Acesso em: 15 ago. 2012

FREUD, Sigmund. Além do princípio do prazer e outros trabalhos. Rio de Janeiro: Imago Editora, Obras completas, 1976.

GILBERT, Jay. The millennials: a new generation of employees, a new set of engagement policies. Ivey Business Journal, 75(5). 26, 2011. Disponível em: http://www.slideshare.net/jeffheil/leadership-strategies-for-millennial-employees. Acesso em 30 ago. 2012

HUIZINGA, Johan. Homo ludens: o jogo como elemento da cultura. São Paulo: Perspectiva, 2001.

JOHNSON, David; JOHNSON, Roger; SMITH, Karl. A Aprendizagem Cooperativa Retorna às Faculdades. in Change, Jul/Aug98, Vol. 30, Issue 4, p26. Disponível em http://www.andrews.edu/ freed/ppdfs/ readings.pdf. Acesso em: 10 ago. 2012.

KUPPERSCHMIDT Betty R. Multigeneration Employees: strategies for effective management. The Health Care Manager 19(1): 65-76, 2000.

LANCASTER, Lynne C.; STLLMAN, David. When generations collide: who they are why they clash. how to solve the generational puzzle at work. New York: HarperCollins Publishers, 2005.

LEWIN, Kurt. A dynamic theory of personality. New York: McGraw Hill, 1935.

LOMBARDIA, Pilar García; STEIN, Guido; PIN, José Ramón. Politicas para dirigir los nuevos professionales: motivaciones y valores de la generación Y. Barcelona: IESE Business Scholl - Universidad de Navarra, 2008. 19 p. Disponível em: http://www.iese.edu/research/ pdfs/DI-0753.pdf. Acesso em: 30 ago. 2012.

MCGUIRE, David; BY, Rune. Todnem; HUTCHINGS, Kate (2007). Towards a model of human resource solutions of achieving intergen- erational interaction in organizations. Journal of European Industrial Training, 31 (8), p. 592-608.

MALHOTRA, Naresh K. Pesquisa de marketing: uma orientação aplicada. 4. ed. Porto Alegre: Bookman, 2004.

MOITA, Filomena Maria Gonçalves da S. Cordeiro. Games: contexto cultural e curricular juvenil. 2006. 181f. Tese (Doutorado em Educação) - Programa de Pós Graduação da Universidade Federal da Paraíba UFPA, João Pessoa, 2006.

MORAIS Jr; Arioston Araújo de. Elaboração de um analisador virtual utilizando sistema híbrido neuro fuzzy para inferenciar a composição num processo de destilação. 2011. 160f. Dissertação (Mestrado em Engenharia Química). Universidade Federal de Alagoas - UFAL, Alagoas, 2011. Disponível em: http:/www.ctec.ufal.br/posgraduacao/ ppgeq/dissertacao_arioston.pdf. Acesso em: 17 set. 2012.

MORAIS, Wellerson Rezende; ASSIS, Ricardo Luis Aguiar. Os jogos eletrônicos: artefatos culturais, tecnológicos e virtuais na sociedade da era digital. CEFET-MG. Belo Horizonte. 2008.

MOTTA, Alda Brito da; Weller, Wivian. A atualidade do conceito de gerações na pesquisa sociológica. Sociedade e Estado, Brasilia, v. 25, n. 2. , Aug. 2010. Disponível em: http://www.scielo.br/scielo. php? script $=$ sci_arttext\&pid=S0102-69922010000200003\&lng=en\& nrm=iso. Acesso em: 30 Ago. 2012.

NORA, Luiz Fernando Zen; ARNOLDI, Paulo Roberto Colombo. $A$ constituição federal e princípios para o cooperativismo na economia solidária. UNESP - SP. São Paulo. 2004.

OLIVEIRA, Sidnei. Geração y: o nascimento de uma nova versão de líderes. 2. ed. São Paulo, Integrare, 2010.

PIAGET, Jean. A construção do real na criança. 2.ed. Rio de Janeiro: Zahar, 1975.

J. O juízo moral na criança. São Paulo: Summus, 1994.

PLATTEAU, Eva; MOLENVELD, Astrid; DEMUZERE, Sara. Do generational differences regarding organizational culture affect intergenerational conflict? a quantitative study in a local government organization. In: ANNUAL INTERNATIONAL ASSOCIATION OF CONFLICT MANAGEMENT CONFERECE ISTANBUL, 7, 2011, Istanbul. Anais eletrônicos... Turquia: 2011.

RODRIGUES, Aroldo. Psicologia social. Petrópolis : Vozes, 1986.

ROBBINS, Stephen. Comportamento organizacional. 14. Ed. São Paulo: Pearson Prentice Hall, 2011.

RAMOS, Daniela. K. A escola frente ao fenômeno dos jogos eletrônicos: aspectos morais e éticos. CINTED-UFRGS. Novas Tecnologias na Educação.V.6 N 1, Julho, 2008.

RUGIMBANA, Robert. Generation y: how cultural values can be used to predict their choice of electronic financial services. Journal of Financial Services Marketing, v. 11, n.4, p. 301-313(13), 2007.

SATO, Leny et al. As tramas psicossociais da cooperação e da competição em diferentes contextos de trabalho. Arquivos Brasileiros de Psicologia (UFRJ. 2003), v. 63, p. 2-14, 2011.

SHAW, Sue; FAIRHURST, David. Engaging a new generation of graduates. Educating Training, v. 50, n. 5, 2008.

SIITONEN, Marko. Building and experiencing community in internetbased multiplayer computer games. Miami Beach: National Communication Association, 2003.

SMOLA, K. W.; SUTTON, C. D. Generational differences: revisiting generational work values for the new Millennium. Journal of Organizational Behavior, v. 23, n. 4, pp. 363-382, 2002.

SUZUKI, Fernanda Tomie Icassati et al. O uso de videogames, jogos de computador e internet por uma amostra de universitários da Universidade de São Paulo. J. bras. psiquiatr., Rio de Janeiro, v. 58, n. 3, 2009. Disponível em: http://www.scielo.br/scielo.php?script=sci arttext\&pid=S0047-20852009000300004\&lng=en\&nrm=iso. Acesso em: 15 jun 2012. 
VASCONCELOS, Kátia Cyrlene de Araújo et al. A Geração Y e suas âncoras de carreira. Revista Eletrônica de Gestão Organizacional, Recife, v. 8, n. 2, p.

WINNICOTT, D.W. O brincar e a realidade. Rio de Janeiro: Imago, 1975.

YEE, Nicolas. The Psychology of MMORPGs: Emotional Investment, Motivations, Relationship Formation, and Problematic Usage. In: R. Schroeder \& A. Axelsson (Eds.), Avatars at Work and Play: Collaboration and Interaction in Shared Virtual Environments (pp. 187-207). London, Springer-Verlag, 2006. Disponível em: http:// www.hci.iastate.edu/REU09/pub/Main/723/yee-psychology-mmorpg. pdf. Acesso em: 30 ago. 2012. 